Published in final edited form as:

Am J Clin Oncol. 2018 May ; 41(5): 432-440. doi:10.1097/COC.0000000000000301.

\title{
Retrospective Analysis of Cisplatin Nephrotoxicity in Patients with Head and Neck Cancer Receiving Outpatient Treatment with Concurrent High-Dose Cisplatin and Radiotherapy
}

\author{
Jennifer Faig, MD¹, Michael Haughton, MD², Richard C. Taylor, MD³, Ralph B. D’Agostino \\ Jr, PhD ${ }^{4}$, Megan J. Whelen, MPH ${ }^{5}$, Kori Anahi Porosnicu Rodriguez ${ }^{1}$, Marcelo Bonomi, \\ MD², Mariana Murea, MD ${ }^{6}$, and Mercedes Porosnicu, MD ${ }^{2, *}$ \\ ${ }^{1}$ Wake Forest School of Medicine, Medical Center Boulevard, Winston-Salem, NC 27157 \\ ${ }^{2}$ Department of Internal Medicine, Section on Hematology and Oncology, Wake Forest School of \\ Medicine, Medical Center Boulevard, Winston-Salem, NC 27157 \\ ${ }^{3}$ Department of Internal Medicine, Wake Forest School of Medicine, Medical Center Boulevard, \\ Winston-Salem, NC 27157 \\ ${ }^{4}$ Division of Public Health Sciences, Department of Biostatistical Sciences, Wake Forest \\ University Health Sciences, Medical Center Boulevard, Winston-Salem, NC 27157 \\ ${ }^{5}$ Comprehensive Cancer Center of Wake Forest University, Medical Center Boulevard, Winston- \\ Salem, NC 27157 \\ ${ }^{6}$ Department of Nephrology, Wake Forest School of Medicine, Medical Center Boulevard, \\ Winston-Salem, NC 27157
}

\section{Abstract}

Objectives-Cisplatin remains the pivotal chemotherapy in squamous cell carcinoma of the head and neck (SCCHN), with nephrotoxicity considered the dose-limiting toxicity. The purpose of our study was to propose an outpatient high-dose cisplatin (op-HD-cis) protocol aimed at preventing nephrotoxicity and to analyze the results of its utilization in patients with SCCHN treated with concurrent radiotherapy.

Methods-We retrospectively evaluated 82 SCCHN patients treated with op-HD-cis concurrent with radiotherapy at our institution. Acute kidney injury (AKI) and chronic kidney disease (CKD) were defined by Kidney Disease Improving Global Outcomes criteria. Associated factors were

Corresponding Author: Mercedes Porosnicu, MD, Medical Center Boulevard, Winston-Salem, NC 27157, Phone: 336-716-8664, Fax: 336-7165687, mporosni@ wakehealth.edu.

Dr. Faig's current address: Icahn School of Medicine at Mount Sinai, One Gustave L. Levy Place, New York, NY 10029

Ms. Porosnicu Rodriguez's current address: Columbia University in the City of New York, $116^{\text {th }}$ Street and Broadway, New York, NY 10027

Conflicts of Interest: None declared.

\section{SUPPLEMENTAL DIGITAL CONTENT LIST}

Supplemental Digital Content 1. docx

Supplemental Digital Content 2. docx

Supplemental Digital Content 3. docx

Supplemental Digital Content 4. docx 
identified using analysis of covariance models for categorical variables and adjusted Pearson correlations for continuous variables.

Results-The incidence of AKI during treatment was 34.2\%. With a median follow-up of 25.7 months, the average decrease in eGFR was $12.57 \mathrm{ml} / \mathrm{min} / 1.73 \mathrm{~m}^{2}(\mathrm{SD}=18.58)$. At 1 -year and at last follow-up, $5.4 \%$ and $4.4 \%$ of patients had eGFR $<60 \mathrm{ml} / \mathrm{min} / 1.73 \mathrm{~m}^{2}$, respectively. Predictors associated with AKI and CKD were: lower baseline weight and creatinine, higher baseline creatinine clearance, smoking, female gender, African American race, hypertension, and increased hydration and magnesium replacement requirements.

Conclusions-We encountered limited early and late nephrotoxicity. Importantly, nephrotoxicity was not the main dose-limiting toxicity. Our results emphasize the importance of close monitoring and additional replacement of water and electrolytes as needed. A consistent method of measuring and reporting chemotherapy-induced nephrotoxicity would be a valuable contribution to the literature.

\section{Keywords}

head and neck cancer; cisplatin; radiotherapy; nephrotoxicity; acute kidney injury; chronic kidney disease

\section{INTRODUCTION}

Concurrent chemoradiotherapy (CRT) is considered standard treatment for patients with squamous cell carcinoma of the head and neck (SCCHN). Cisplatin remains the mainstay chemotherapeutic agent, preferentially involving high doses (HD-cis). ${ }^{1-3}$ Added to radiotherapy (RT), cisplatin increases the incidence of acute and long-term toxicities, with nephrotoxicity being the drug-specific and dose-limiting adverse effect. ${ }^{4-7}$

Cisplatin concentration is reportedly five times higher in the kidneys than in blood, ${ }^{8,9}$ affecting ion and water transporters. ${ }^{10}$ Patients experience polyuria, degrees of salt-wasting, hypomagnesemia, hypokalemia, hypotension and consequently decreased creatinine $(\mathrm{Cr})$ clearance. ${ }^{8,11-14}$ Volume expansion with isotonic saline infusion and electrolyte replacement is the most effective preventive strategy. ${ }^{8-10,15-18}$

The FDA-regulated cisplatin approval document recommends aggressive fluid resuscitation of $1-2 \mathrm{~L} 0.9 \%$ saline infused over 8-12 hours prior to cisplatin, followed by oral hydration to maintain adequate urine output over next 24 hours. ${ }^{8}, 19$ Historically, patients were hospitalized for cisplatin administration. Current practice is to administer HD-cis as outpatient (op-HD-cis). This has been facilitated by the development of potent anti-emetics.

Controversy remains over outpatient schedule and optimal dose and duration of fluid and electrolytes replacement. Few publications are available presenting outpatient cisplatin regimens. ${ }^{9,}$ 19-21 Tiseo et al showed that outpatient HD-cis was safe with short-term hydration ( $2 \mathrm{~L}$ isotonic saline over $4 \mathrm{~h}$ ) in patients with lung cancer. This issue remains unaddressed in patients with SCCHN undergoing CRT. This is of distinct importance, since maintaining adequate hydration is difficult in this patient population. CRT of the head and neck causes mucositis, dysphagia and nausea, which significantly limit oral hydration, 
increasing risk of nephrotoxicity. Consequently, there is a trend in current practice towards employing more fractionated schedules for cisplatin administration (weekly, daily), although not tested in large clinical trials. We developed a protocol for op-HD-cis that involved preventive saline hydration and electrolyte replacement the first 96 hours after cisplatin, the timeframe most critical in acute kidney injury (AKI) prevention. ${ }^{14,19,22}$ In addition, our regimen utilized patients' daily visits for RT for careful monitoring of renal and electrolyte parameters with replacement as needed.

Developing protocols aimed at preventing nephrotoxicity is challenging, with few published protocols described in sufficient detail for comparison and inconsistent methods of analyzing nephrotoxicity. In this retrospective study, we (1) described the administration of fluid and electrolyte resuscitation per our institutional protocol in patients with SCCHN receiving concurrent RT and op-HD-cis; (2) analyzed the incidence of AKI, electrolyte abnormalities, and chronic kidney disease (CKD); and (3) identified factors associated with development of $\mathrm{AKI}$ and CKD.

\section{MATERIALS AND METHODS}

\section{Study design}

This retrospective analysis was approved by our Institutional Review Board. All consecutive patients with SCCHN treated with op-HD-cis according to our protocol concurrent with primary or adjuvant RT between January 2008 and September 2012 were identified in our cancer registry. HD-cis was defined as $775 \mathrm{mg} / \mathrm{m}^{2}$. Patients who received at least one administration of op-HD-cis concurrent with RT were analyzed for AKI. Adjuvant chemotherapy was allowed for this sub-analysis. Patients who received at least two administrations of op-HD-cis concurrent with RT, no induction or adjuvant chemotherapy, and had a minimum follow-up of three months were analyzed for CKD.

\section{Outpatient high-dose cisplatin regimen}

The op-HD-cis protocol is summarized in Table 1. Op-HD-cis was administered every 3 weeks starting with day 1 of RT. Adjuvant RT was given at 60-66 Gy over 6-6.5 weeks. Definitive RT was given at 70Gy over 7 weeks. Normal estimated glomerular filtration rate (eGFR) calculated by standard laboratory formula (IDMS traceable MDR) was ensured prior to treatment. Pre-hydration with $1,000 \mathrm{~mL}$ normal saline (NS) over $1-2 \mathrm{~h}$ was administered to establish euvolemia before CRT. ${ }^{22}$ Cisplatin was then infused at a target dose of $100 \mathrm{mg} / \mathrm{m}^{2}$ in $500 \mathrm{~mL}$ of $0.45 \% \mathrm{NS}$ with $12.5 \mathrm{~g}$ of mannitol. Starting in 2012, mannitol was not administered due to drug shortage. No other diuretic was used. Cisplatin dose was calculated using actual body weight per ASCO guidelines. The post-hydration regimen consisted of $1,000 \mathrm{~mL}$ NS containing $20 \mathrm{mEq}$ of potassium chloride and $16 \mathrm{mEq}$ of magnesium sulfate. Patients returned to receive $1,500 \mathrm{~mL}$ NS on day 2 and on days 3 or 4 post-cisplatin treatment, with electrolyte replacement as needed based on basic metabolic panel and magnesium ( $\mathrm{Mg}$ ) levels. In rare instances of scheduling conflicts (i.e. weekends), patients were encouraged to maintain adequate fluid intake until first available visit. Fosaprepitant and decadron were given as supportive medications to all patients. A 5- $\mathrm{HT}_{3}$ antagonist (Ondansetron) was prescribed as needed. Patients were encouraged to maintain adequate 
fluid intake and returned to clinic weekly for physical exam and blood tests. Electrolytes were replaced as needed and additional hydration was given if patients showed signs of hypovolemia, were unable to maintain adequate fluid intake, or had increased blood urea nitrogen/Cr ratio (BUN/Cr) 20 . Patients were called for additional hydration visits when AKI was diagnosed. Cisplatin was adjusted (discontinued, delayed or dose decreased), depending on severity of AKI, recovery and patient compliance.

\section{Retrospective data collection}

The following electronic medical records data were recorded: age at SCCHN diagnosis, gender, race, tobacco use, TNM stage, highest grade of mucositis, body mass index (BMI), history of hypertension or diabetes mellitus, statin use, cumulative cisplatin dose, total amount of fluid and electrolyte replacement, serum $\mathrm{Cr}$ ( $\mathrm{SCr}$ ) before each dose of op-HD-cis (baseline) and post-treatment (days 2, 3, or 4), and maximum $\mathrm{SCr}$ level for each cycle. Other laboratory parameters included nadir serum $\mathrm{Mg}$, sodium $(\mathrm{Na})$, potassium $(\mathrm{K})$, and BUN/ $\mathrm{Cr} \geq 20$ for each cycle. SCr level at 1-year ( \pm 4 months) and last available value, and serum $\mathrm{Mg}, \mathrm{K}$ and $\mathrm{Na}$ levels at 6 months were noted. Patient weights were recorded at start, end, and three months after CRT. Patients were considered smokers (current or recent) if they were actively smoking, or had more than a ten pack-year history and had quit less than one year before diagnosis.

\section{Definition of AKI and CKD}

$\mathrm{SCr}$ rather than $\mathrm{Cr}$ clearance was used to measure AKI because of significant changes in weight before, during, and immediately after treatment. Cisplatin-related AKI was defined based on peak SCr after each op-HD-cis administration. AKI was staged according to Kidney Disease Improving Global Outcomes (KDIGO) criteria ${ }^{23}$ : 0: $\mathrm{Cr}<1.5 \times$ baseline; 1 : $\mathrm{Cr}=1.5-1.9 \times$ baseline; 2 : $\mathrm{Cr}=2.0-2.9 \times$ baseline; $3: \mathrm{Cr} \geq 3.0 \times$ baseline.

CKD was measured according to KDIGO 2012 Clinical Practice Guideline ${ }^{24}$ based on eGFR calculated according to the Chronic Kidney Disease Epidemiology Collaboration (CKD-EPI) formula ${ }^{25}$ (Supplemental Digital Content 1, Table 1). CKD is defined as eGFR below $60 \mathrm{ml} / \mathrm{min} / 1.73 \mathrm{~m} 2$ for more than 3 months. eGFR drop is defined as decline of $225 \%$ from baseline. CKD and eGFR drop were evaluated at two time points: 1) a fixed time point of 1-year ( \pm 4 months), which allowed stabilization of kidney function post-treatment, and 2) at last follow-up visit available for each patient, capturing the entire study population. Only patients with follow-up of at least 3 months were included in the study, per KDIGO criteria for chronicity. ${ }^{24}$

\section{Statistical Analysis}

Descriptive statistics were calculated, including means and standard deviations for continuous variables and counts and percentages for categorical variables. AKI was classified as KDIGO Stage 1 or higher and defined by time of occurrence: Cycle 1, Cycle 2 or any time during treatment. Patients with versus without AKI were compared using twosample t-tests for continuous variables and Fisher's exact tests for categorical variables.

CKD was examined by percent change in eGFR (REL-eGFR) at 1-year and at last follow-up relative to baseline. For categorical variables, REL-eGFR was compared using two-sample t- 
tests, and Pearson correlations were used for continuous variables. For comparisons made using the last follow-up visit, REL-eGFR was modeled adjusting for the time-point of measurement. For comparisons of categorical variables, analysis of covariance was used with time included as a covariate, and for comparisons using continuous variables, Pearson correlations were calculated adjusting for time. Electrolyte changes during treatment and at 6 months were examined for patients treated with at least two cycles of cisplatin using paired t-tests. All analyses were performed using SAS Version 9.3 (Cary, NC).

\section{RESULTS}

\section{Patient Characteristics}

Eighty-two patients received at least one cycle of op-HD-cis and were analyzed for AKI. Seventy-one patients received at least two cycles of op-HD-cis and thus qualified for CKD analysis; however, three patients were excluded because they received adjuvant chemotherapy with cisplatin (Supplemental Digital Content 2, Figure 1). Patient demographics and clinical characteristics are summarized in Table 2. Thirty-three patients (40\%) had deviations from scheduled op-HD-cis, with only $6.1 \%$ involving AKI. Other reasons included neutropenia (14.6\%), mucositis (7.3\%), non-compliance, vomiting, and weight loss (Supplemental Digital Content 3, Table 2). Patients with baseline low SCr and high eGFR had significantly lower weight $(\mathrm{p}<0.0001$ and $\mathrm{p}=0.02)$ and $\mathrm{BMI}(\mathrm{p}=0.0001$ and $\mathrm{p}=0.006$ ).

\section{Acute Kidney Injury Analysis}

Any AKI event during treatment-Of the 82 patients, $13 \%$ received 1 cycle, $63 \% 2$ cycles, and 23\% 3 cycles of op-HD-cis (Supplemental Digital Content 2, Figure 1). Thirtyfour percent developed AKI in at least one cycle. Three patients developed AKI after both first and second cycles of op-HD-cis. Twenty-one percent had SCr above upper limits of normal (>1.5 mg/dl) in at least one cycle (Table 2). Figure 1A depicts the distribution of maximum $\mathrm{SCr}$ relative to baseline $\mathrm{SCr}$ for each patient and cycle. Relative to those who did not develop AKI, patients with AKI had significantly lower baseline $\mathrm{SCr}$ (0.9 vs. 0.78 ; $\mathrm{p}=0.002)$, higher initial eGFR ( 91.3 vs. $99.9 ; \mathrm{p}=0.01)$, were more often female $(16.7 \%$ vs. $39.3 \% ; \mathrm{p}=0.03$ ), and smokers ( $31.5 \%$ vs. $60.7 \%$; $\mathrm{p}=0.018$ ) (Table 4$)$. In patients with BMI $>30,27.2 \%$ experienced AKI vs $37.5 \%$ in patients with BMI $\leq 30$. The last six patients treated in 2012 did not receive mannitol due to drug shortage. Four of these patients (66\%) experienced AKI ( $\mathrm{p}=0.015$ ) (data not shown). Of the 28 patients with AKI, $11(39 \%)$ had op-HD-cis deviations (Reasons: the AKI event [5], neutropenia [4], sepsis [1], noncompliance [1]; details in Supplemental Digital Content 3, Table 2).

AKI following first op-HD-cis cycle-Of 82 patients who received one op-HD-cis cycle, 20.7\% experienced AKI after cycle 1 (Table 3). Patients who developed AKI had significantly lower mean baseline $\mathrm{SCr}(0.76$ vs. $0.89 ; \mathrm{p}=0.003)$ and significantly higher baseline eGFR (101.7 vs. 92.1; $\mathrm{p}=0.015)$. Baseline BMI ( $\mathrm{p}=0.06)$ and weight $(\mathrm{p}=0.09)$ were borderline significant (Table 4). Patients with no AKI were, on average, $9.60 \mathrm{~kg}$ heavier. Peak SCr occurred 6.9 and 8.3 days after op-HD-cis for those without and with AKI $(\mathrm{p}=0.07)$. 
AKI following second and third op-HD-cis cycles-Of 71 patients who received at least 2 op-HD-cis, $14 \%$ developed AKI after cycle 2. Patients who developed AKI were more often AA ( $4.9 \%$ vs. $40 \%$; $\mathrm{p}=0.006)$ and female ( $19.7 \%$ vs. $50 \%$; $\mathrm{p}=0.05)$ (Table 4$)$. Of 19 patients who received 3 op-HD-cis, $21 \%$ developed AKI after cycle 3. Average peak SCr occurred at day 5.34 (cycle 2) and 6.8 (cycle 3), with no significant difference between groups.

\section{Chronic Kidney Disease Analysis}

CKD at last follow-up visit-Sixty-eight patients had a median follow-up of 25.7 months (range: 3-60). Average dose of cisplatin was $225.6 \mathrm{mg} / \mathrm{m}^{2}$ and median dose was $200 \mathrm{mg} / \mathrm{m}^{2}$ (95\% CI: 215- 236). Median decrease in last eGFR was $12.3 \mathrm{ml} / \mathrm{min} / 1.73 \mathrm{~m}^{2}$ (IQR $=0.7-$ 21.9 ) and mean \pm SD decrease was $12.6 \pm 18.6 \mathrm{ml} / \mathrm{min} / 1.73 \mathrm{~m}^{2}$ (Table 3). Average amount of hydration (including that administered via op-HD-cis protocol) was 16.1 liters (range, 543.5; $\mathrm{SD}=7.2$ ) and average amount of $\mathrm{Mg}$ sulfate was 47.4 grams (range, 16-192; $\mathrm{SD}=34.5$ ).

Five $(7.3 \%)$ patients had the last eGFR below $60 \mathrm{ml} / \mathrm{min} / 1.73 \mathrm{~m}^{2}$ and in three $(4.4 \%)$ patients this was attributed to op-HD-cis (last eGFR 58,59 and $49 \mathrm{ml} / \mathrm{min} / 1.73 \mathrm{~m}^{2}$ ). Two patients developed co-morbidities that likely contributed to development of CKD (hepato-renal syndrome and nephrectomy for renal cyst). No patient required renal replacement therapy. $19.1 \%$ patients had decrease in last eGFR of $\geq 25 \%$ from baseline (Table 3 ).

Adjusting for duration of follow-up, patients with higher baseline eGFR ( $\mathrm{p}=0.007)$ and lower baseline $\mathrm{SCr}(\mathrm{p}=0.01)$ had larger decrease in eGFR after treatment. These patients required significantly more hydration and $\mathrm{Mg}$ replacement $(\mathrm{p}=0.008$ and $\mathrm{p}=0.04$, respectively). AAs, smokers and patients with lower baseline weight had greater decline in eGFR, approaching statistical significance ( $\mathrm{p}=0.06, \mathrm{p}=0.10$ and $\mathrm{p}=0.06$, respectively) (Table $5)$.

CKD at 1-year post-treatment-Fifty-five of 68 patients had SCr data available at 1year (range: 8-14mo; average: $11.4 \mathrm{mo} ; 11$ patients had follow-up of less than $8 \mathrm{mo}$ and 2 patients were non-compliant with scheduled evaluation in the 8-14mo timeframe). For those patients, the median decrease in 1-year eGFR was 8.7 (IQR $=0.7-21.9$ ) and the mean $\pm \mathrm{SD}$ was $12.2 \pm 17.7$ (Table 3). Average dose of cisplatin was $227.1 \mathrm{mg} / \mathrm{m}^{2}$ and median was 200 $\mathrm{mg} / \mathrm{m}^{2}$ (95\%CI: $\left.215.3-238.9\right)$. The same five patients with decline in last eGFR below 60 $\mathrm{ml} / \mathrm{min} / 1.73 \mathrm{~m}^{2}$ had similar 1-year eGFR levels. Eighteen percent of patients experienced decrease in 1-year eGFR of $\geq 25 \%$. Figure $1 \mathrm{~B}$ presents the 1-year eGFR relative to baseline eGFR for each patient. Females ( $\mathrm{p}=0.04)$, smokers $(\mathrm{p}=0.003)$, hypertensives $(\mathrm{p}=0.04)$, and those requiring more $\mathrm{Mg}$ replacement $(\mathrm{p}=0.04)$ had significantly greater decline in 1-year eGFR (Table 5). There was no significant correlation between patients who developed AKI during treatment and patients who had decline in eGFR $225 \%$ at 1 -year $(\mathrm{p}=0.17)$ or at last follow up $(\mathrm{p}=0.52)$.

\section{Electrolytes and $\mathrm{BUN} / \mathrm{Cr}$ during treatment and at 6 months post-treatment-} Electrolytes and BUN/Cr were analyzed in 68 patients with at least 2 op-HD-cis administrations. Cycle 3 was not analyzed due to small sample size. Average levels of $\mathrm{Na}, \mathrm{K}$ and $\mathrm{Mg}$ were significantly lower after each cycle. At 6 months, all patients normalized K, 7 
patients maintained borderline low $\mathrm{Na}(131-134 \mathrm{mmol} / \mathrm{L})$ and only two patients maintained borderline low $\mathrm{Mg}$ of $1.7 \mathrm{mg} / \mathrm{dl}$. Expectedly, the percentage of patients with $\mathrm{BUN} / \mathrm{Cr} \geq 20$ was high following each op-HD-cis ( $88.2 \%$ and $80.6 \%$ ), but decreased to pre-treatment level within 6 months (35.3\%) (Supplemental Digital Content 4, Table 3).

\section{DISCUSSION}

This retrospective study analyzes an op-HD-cis regimen aimed at preventing acute and chronic kidney toxicity in SCCHN patients. It is particularly challenging for patients with SCCHN receiving CRT to maintain adequate hydration. Oropharyngeal mucositis leads to dysphagia, nausea, and vomiting, yet maintaining adequate hydration is the main method to prevent cisplatin nephrotoxicity. ${ }^{8-10,15-18}$ Poor nutritional and hydration status at time of diagnosis can further increase the risk of AKI. Our op-HD-cis protocol employs close monitoring and supplementation of fluids and electrolytes, facilitated by daily visits for radiotherapy. Initial "preventive" rigorous hydration regimen addresses the first 96 hours demonstrated to be a vulnerable period for development of kidney toxicity. ${ }^{14,19,22}$ The second "responsive" phase, represented by replacement of water and electrolytes as needed, is of equal importance in the SCCHN population.

Large prospective studies involving similar patient populations treated with HD-cis concurrent with RT report on nephrotoxicity; however, limited information is provided to allow for protocol comparisons, underscoring the need for a consistent method of measuring and reporting chemotherapy-induced nephrotoxicity. We analyzed nephrotoxicity utilizing KDIGO criteria and provided results compatible with other measurement methods reported in literature as exemplified below.

Approximately one-third of our participants experienced at least one AKI event during chemotherapy as defined by KDIGO criteria. If AKI was defined by increase in creatinine above normal level for the measuring laboratory, the incidence would be $21 \%$. These results are comparable to inpatient hydration regimens. A retrospective study evaluating 62 patients with SCCHN treated inpatient with cisplatin and 5-fluorouracil with concurrent radiation reported nephrotoxicity incidence of $37 \%$ after first cycle and $46 \%$ after one or two cycles. ${ }^{10}$ Nephrotoxicity was defined in this study as increase in SCr by more than $0.5 \mathrm{mg} / \mathrm{dl}$ from baseline. Employing the same definition of AKI, our results compare favorably with an incidence of nephrotoxicity of $14.6 \%$ after cycle 1 and $28.1 \%$ after one or two cycles. In a large prospective randomized study, ${ }^{26}$ late kidney toxicity was measured by creatinine level and graded according to Radiation Therapy Oncology Group Common Toxicity Criteria. Reported incidence of grade 1 or more toxicity (creatinine level above $1.5 \times$ normal) was $18 \%$. We report only two findings of grade 1 toxicity measured by the same criteria, and these events were found in two patients who developed renal co-morbidities within the first year of CRT. In another retrospective report of SCCHN patients treated with HD-cis concurrent with RT, higher incidences of AKI (53.7\%) and CKD (29.6\%) were reported. ${ }^{27}$ It was not clear whether HD-cis was given as outpatient or inpatient. In addition, stricter criteria for $\mathrm{AKI}$ and a different formula to calculate creatinine clearance and define $\mathrm{CKD}$ were utilized, precluding direct comparisons. 
Previous reports showed that $25-35 \%$ of patients with various malignancies treated with single dose cisplatin infusion develop a decrease in GFR. ${ }^{8,28}$ Moreover, a persistent reduction in GFR by $20 \%-30 \%$ was shown in long-term follow-up studies ${ }^{28}$ and irreversible renal damage was reported in about a third of patients. ${ }^{6}$ The CKD-EPI formula was elected to estimate GFR in study patients given that baseline $\mathrm{SCr}$ was within normal limits. With a median follow-up of $25.7 \mathrm{mo}$, the average decrease in eGFR was $12.57 \mathrm{ml} / \mathrm{min} / 1.73 \mathrm{~m}^{2}$. While likely not clinically relevant for the majority of patients, it compares well with previously reported averages of 12.5 to $29 \mathrm{ml} / \mathrm{min} / 1.73 \mathrm{~m}^{2} .{ }^{28}$ We reported an incidence of eGFR decline by $225 \%$ comparative to baseline in $19.1 \%$ of patients at last follow-up and $18 \%$ of patients eligible for 1-year evaluation. The incidence of mild-moderate CKD per KIDGO criteria in our study was $5.4 \%$ at 1 -year and $4.4 \%$ at last follow-up.

Although there is a consistent theme in the literature about cisplatin nephrotoxicity leading to cisplatin dose limitation, $8,9,29,30$ we reported only $6.1 \%$ of patients having chemotherapy changes caused by nephrotoxicity. In our series, deviations from scheduled op-HD-cis were caused primarily by neutropenia, then mucositis, and lastly by AKI. AKI did not appear to be associated with other complications that led to treatment alterations: mucositis did not cause cisplatin changes in any patients with AKI, and neutropenia caused similar alterations in patients with or without AKI (14.3\% vs 13\%). Further, there was no significant correlation between patients with any AKI and patients with eGFR drop $225 \%$. These findings support the efficacy of our op-HD cis protocol.

Our protocol incorporated early SCr and electrolytes monitoring with scheduled hydration. In this context, $\mathrm{SCr}$ nadir was on average one week post-treatment with a wide range (days 2 to 18). This finding underlines the importance of scheduling weekly follow-up assessments of kidney function with embedded time for hydration and electrolytes replacement as needed. Mg wasting has been reported as the most common electrolyte abnormality during treatment with cisplatin. ${ }^{11}$ Moreover, long-lasting hypomagnesemia has been reported after treatment with cisplatin, up to 10 years. ${ }^{31,32}$ In our study, all but two patients had Mg levels within normal limits at 6 months post-treatment, raising the hypothesis that adequate early $\mathrm{Mg}$ replacement might prevent later losses.

In our analysis, patients with low baseline $\mathrm{SCr}$ and high eGFR were significantly more susceptible to AKI. These patients had significantly lower baseline weight and BMI. We believe that this correlation is an artifact of apparently low $\mathrm{SCr}$ due to weight loss with decreased muscle mass and low protein intake that patients often experience prior to cancer diagnosis. During cycle 1, patients that did not experience AKI were, on average, $9.6 \mathrm{~kg}$ heavier than patients who did $(\mathrm{p}=0.09)$ with a difference in BMI close to statistical significance $(\mathrm{p}=0.06)$. Patients with BMI $>30$ had fewer AKI events despite cisplatin dose being calculated based on actual body weight. This finding should caution against misinterpretation of a low SCr level, especially in a patient with low BMI and weight, which could lead to inadequate hydration and kidney function monitoring. In a multivariate regression analysis, weight, $\mathrm{SCr}$ and eGFR lost statistical significance for association with AKI or CKD preventing definite conclusions (data not shown). 
Similar with other studies, female gender, smoking and AA race were associated with worse kidney outcomes. ${ }^{5,10}$ Although statistical significance was not reached in all AKI analyses, it is important to underline that 6 of $8 \mathrm{AA}$ patients presented at least one AKI event during treatment, with statistical significance reached for the independent analysis of cycle 2 $(\mathrm{p}=0.006)$. Similar predictors of AKI correlated with worse long-term outcome of kidney function defining progressive CKD: current smoking status, AA race, female gender, initial lower weight, $\mathrm{SCr}$ and higher eGFR. In addition, patients with hypertension expectedly had a greater decline in eGFR at 1-year $(\mathrm{p}=0.04)$.

Several studies showed that statins ${ }^{32,33}$ could protect against cisplatin-induced nephrotoxicity. Approximately a quarter of patients took statins, however there was no protective effect on AKI or CKD.

The efficacy of osmotic diuretics, in particular mannitol, for preventing nephrotoxicity remains unclear. ${ }^{4,9,18,20,34}$ Our initial protocol included mannitol; however, it was not received by six patients due to supply shortages. Unexpectedly, four of the six patients had AKI during treatment ( $66 \%$ vs. $31.5 \%$ in patients treated with mannitol). This is a low number of patients but revives old controversies.

Our study describes an op-HD-cis protocol, and our findings, though retrospective and obtained using calculated eGFR as opposed to more precise direct measurements of the true glomerular filtration, show limited early and late nephrotoxicity in SCCHN patients treated with CRT. Importantly, nephrotoxicity was not the main dose-limiting toxicity. Our results emphasize the importance of close monitoring and additional hydration and electrolyte replacement as needed. Low baseline SCr in patients with low body weight should not decrease the protocol intensity. Future effort is needed in consistently measuring and reporting chemotherapy-induced nephrotoxicity.

\section{Supplementary Material}

Refer to Web version on PubMed Central for supplementary material.

\section{Acknowledgments}

The authors wish to thank Bonny B. Morris, MSPH for her thoughtful manuscript review.

Source of Funding: Biostatistical services supported by the Comprehensive Cancer Center of Wake Forest University NCI CCSG P30CA012197 grant.

\section{References}

1. Adelstein DJ, Li Y, Adams GL, et al. An intergroup phase III comparison of standard radiation therapy and two schedules of concurrent chemoradiotherapy in patients with unresectable squamous cell head and neck cancer. J Clin Oncol. 2003; 21:92-98. [PubMed: 12506176]

2. Bernier J, Domenge C, Ozsahin M, et al. Postoperative irradiation with or without concomitant chemotherapy for locally advanced head and neck cancer. New Engl J Med. 2004; 350:1945-1952. [PubMed: 15128894]

3. Cooper JS, Pajak TF, Forastiere AA, et al. Postoperative concurrent radiotherapy and chemotherapy for high-risk squamous-cell carcinoma of the head and neck. New Engl J Med. 2004; 350:19371944. [PubMed: 15128893] 
4. Loehrer PJ, Einhorn LH. Drugs five years later. Cisplatin. Ann Int Med. 1984; 100:704-713. [PubMed: 6370067]

5. Mathe C, Bohacs A, Duffek L, et al. Cisplatin nephrotoxicity aggravated by cardiovascular disease and diabetes in lung cancer patients. Eur Respir J. 2011; 37:888-894. [PubMed: 20650984]

6. Razzaque MS. Cisplatin nephropathy: is cytotoxicity avoidable? Nephrol Dial Transplant. 2007; 22:2112-2116. [PubMed: 17617652]

7. Saleh S, Ain-Shoka AA, El-Demerdash E, Khalef MM. Protective effects of the angiotensin II receptor blocker losartan on cisplatin-induced kidney injury. Chemotherapy. 2009; 55:399-406. [PubMed: 19955745]

8. dos Santos NA, Carvalho Rodrigues MA, Martins NM, dos Santos AC. Cisplatin-induced nephrotoxicity and targets of nephroprotection: an update. Arch Toxicol. 2012; 86:1233-1250. [PubMed: 22382776]

9. Santoso JT, Lucci JA 3rd, Coleman RL, Schafer I, Hannigan EV. Saline, mannitol, and furosemide hydration in acute cisplatin nephrotoxicity: a randomized trial. Cancer Chemother Pharmacol. 2003; 52:13-18. [PubMed: 12719883]

10. Shord SS, Thompson DM, Krempl GA, Hanigan MH. Effect of concurrent medications on cisplatin-induced nephrotoxicity in patients with head and neck cancer. Anticancer drugs. 2006; 17:207-215. [PubMed: 16428940]

11. Goren MP. Cisplatin nephrotoxicity affects magnesium and calcium metabolism. Med Pediatr Oncol. 2003; 41:186-189. [PubMed: 12868117]

12. Lajer H, Kristensen M, Hansen HH, et al. Magnesium depletion enhances cisplatin-induced nephrotoxicity. Cancer Chemother Pharmacol. 2005; 56:535-542. [PubMed: 15947931]

13. Lin A, Jabbari S, Worden FP, et al. Metabolic abnormalities associated with weight loss during chemoirradiation of head-and-neck cancer. Int J Radiat Oncol Biol Phys. 2005; 63:1413-1418. [PubMed: 16109461]

14. Miller RP, Tadagavadi RK, Ramesh G, Reeves WB. Mechanisms of Cisplatin nephrotoxicity. Toxins (Basel). 2010; 2:2490-2518. [PubMed: 22069563]

15. Bodnar L, Wcislo G, Gasowska-Bodnar A, Synowiec A, Szarlej-Wcislo K, Szczylik C. Renal protection with magnesium subcarbonate and magnesium sulphate in patients with epithelial ovarian cancer after cisplatin and paclitaxel chemotherapy: a randomised phase II study. Eur J Cancer. 2008; 44:2608-2614. [PubMed: 18796350]

16. Furukawa N, Kawaguchi R, Kobayashi H. Use of high-dose cisplatin with aprepitant in an outpatient setting. Eur J Cancer Care. 2012; 21:436-441.

17. Hanigan MH, Deng M, Zhang L, Taylor PT Jr, Lapus MG. Stress response inhibits the nephrotoxicity of cisplatin. Am J Physiol Renal Physiol. 2005; 288:F125-F132. [PubMed: 15353400]

18. Polycarpe E, Arnould L, Schmitt E, et al. Low urine osmolarity as a determinant of cisplatininduced nephrotoxicity. Int J Cancer. 2004; 111:131-137. [PubMed: 15185354]

19. Tiseo M, Martelli O, Mancuso A, et al. Short hydration regimen and nephrotoxicity of intermediate to high-dose cisplatin-based chemotherapy for outpatient treatment in lung cancer and mesothelioma. Tumori. 2007; 93:138-144. [PubMed: 17557559]

20. Hansen SW, Groth S, Daugaard G, Rossing N, Rorth M. Long-term effects on renal function and blood pressure of treatment with cisplatin, vinblastine, and bleomycin in patients with germ cell cancer. J Clin Oncol. 1988; 6:1728-1731. [PubMed: 2460594]

21. Hotta K, Takigawa N, Hisamoto-Sato A, et al. Reappraisal of short-term low-volume hydration in cisplatin-based chemotherapy: results of a prospective feasibility study in advanced lung cancer in the Okayama Lung Cancer Study Group Trial 1002. Jpn J Clin Oncol. 2013; 43:1115-1123. [PubMed: 24082005]

22. Launay-Vacher V, Rey JB, Isnard-Bagnis C, Deray G, Daouphars M. Prevention of cisplatin nephrotoxicity: state of the art and recommendations from the European Society of Clinical Pharmacy Special Interest Group on Cancer Care. Cancer Chemother Pharmacol. 2008; 61:903909. [PubMed: 18317762]

23. Okusa MD, Davenport A. Reading between the (guide)lines--the KDIGO practice guideline on acute kidney injury in the individual patient. Kidney Int. 2014; 85:39-48. [PubMed: 24067436] 
24. Kidney Disease: Improving Global Outcomes (KDIGO) CKD Work Group. KDIGO 2012 Clinical Practice Guideline for the Evaluation and Management of Chronic Kidney Disease. Kidney Int. 2013; 3:1-150.

25. Levey AS, Stevens LA, Schmid CH, et al. A new equation to estimate glomerular filtration rate. Ann Intern Med. 2009; 150:604-612. [PubMed: 19414839]

26. Cooper JS, Zhang Q, Pajak TF, et al. Long-term follow-up of the RTOG 9501/intergroup phase III trial: postoperative concurrent radiation therapy and chemotherapy in high-risk squamous cell carcinoma of the head and neck. Int J Radiat Oncol Biol Phys. 2012; 84:1198-1205. [PubMed: 22749632]

27. Espeli V, Zucca E, Ghielmini M, et al. Weekly and 3-weekly cisplatin concurrent with intensitymodulated radiotherapy in locally advanced head and neck squamous cell cancer. Oral Oncol. 2012; 48:266-271. [PubMed: 22079100]

28. Hartmann JT, Kollmannsberger C, Kanz L, Bokemeyer C. Platinum organ toxicity and possible prevention in patients with testicular cancer. Int J Cancer. 1999; 83:866-869. [PubMed: 10597214]

29. Forastiere AA, Goepfert H, Maor M, et al. Concurrent chemotherapy and radiotherapy for organ preservation in advanced laryngeal cancer. N Engl J Med. 2003; 349:2091-2098. [PubMed: 14645636]

30. Cubillo A, Cornide M, Lopez JL, et al. Renal tolerance to cisplatin in patients 70 years and older. Am J Clin Oncol. 2001; 24:192-197. [PubMed: 11319297]

31. Schilsky RL, Barlock A, Ozols RF. Persistent hypomagnesemia following cisplatin chemotherapy for testicular cancer. Cancer Treat Rep. 1982; 66:1767-1769. [PubMed: 6889461]

32. Ali BH, Al Moundhri MS. Agents ameliorating or augmenting the nephrotoxicity of cisplatin and other platinum compounds: a review of some recent research. Food Chem Toxicol. 2006; 44:11731183. [PubMed: 16530908]

33. Fujieda M, Morita T, Naruse K, et al. Effect of pravastatin on cisplatin-induced nephrotoxicity in rats. Hum Exp Toxicol. 2011; 30:603-615. [PubMed: 20650967]

34. Morgan KP, Buie LW, Savage SW. The role of mannitol as a nephroprotectant in patients receiving cisplatin therapy. Ann Pharmacother. 2012; 46:276-281. [PubMed: 22298599] 
A

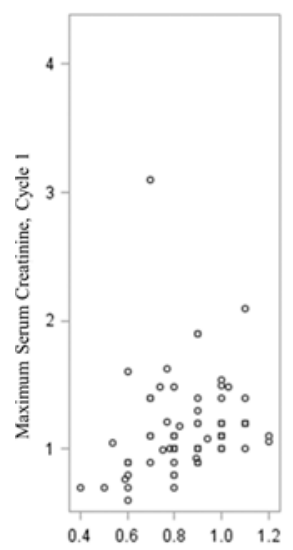

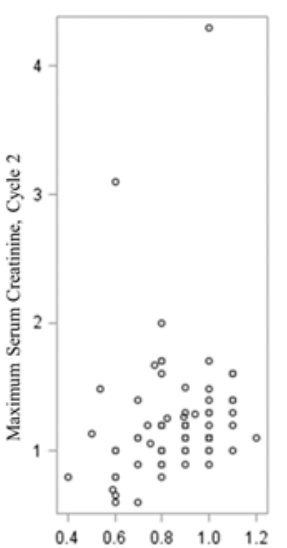

Baseline Serum Creatinine
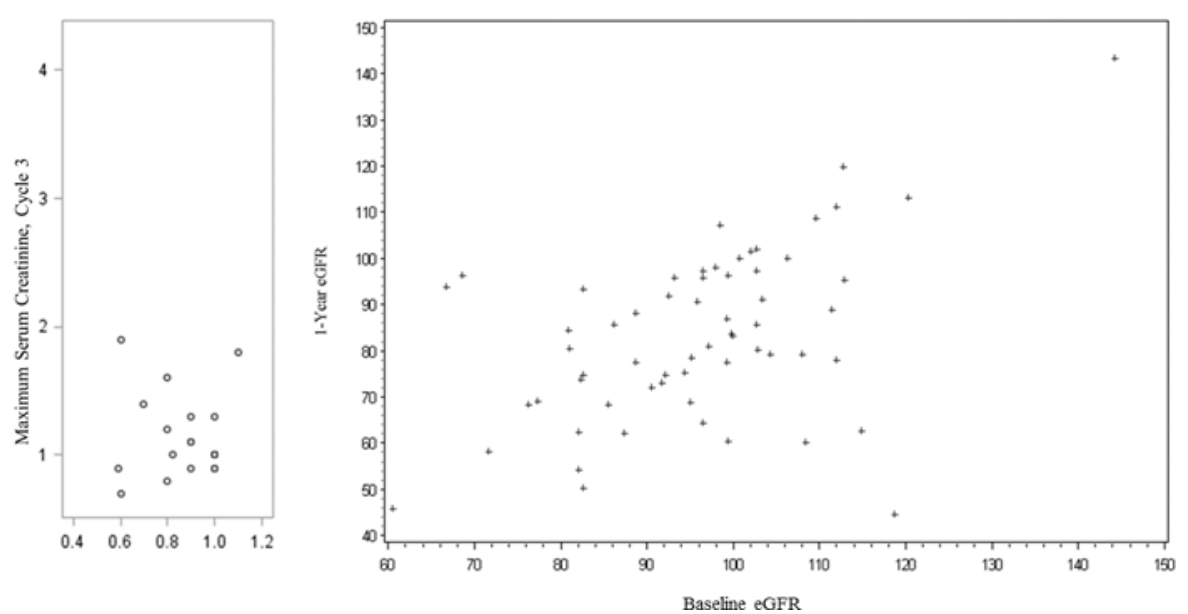

Figure 1.

Distribution of patients for AKI and CKD analysis

$\mathrm{AKI}=$ acute kidney injury; $\mathrm{CKD}=$ chronic kidney disease

A. Correlation of maximum serum creatinine with baseline serum creatinine for each cycle

B. Correlation of eGFR at 1 year with baseline eGFR. eGFR = estimated glomerular filtration rate 


\section{Table 1}

Protocol for administration of op-HD-cis.

\begin{tabular}{|c|c|c|c|}
\hline & Treatment & Hydration & Electrolytes \\
\hline PREVENTIVE & Scheduled visits & & \\
\hline \multirow[t]{3}{*}{ Day 1} & Cisplatin $100 \mathrm{mg} / \mathrm{m}^{2}$ & $\begin{array}{l}\text { Pre-treatment: } 1,000 \\
\text { ml NS over } 1-2 \text { hours }\end{array}$ & $\begin{array}{l}\text { Potassium Chloride } \\
20 \mathrm{mEq} \\
+\end{array}$ \\
\hline & & $\begin{array}{l}\text { During treatment: } \\
12.5 \mathrm{~g} \text { mannitol in } \\
0.45 \% \text { NS } 500 \mathrm{~mL} \\
\text { over } 1 \text { hour }\end{array}$ & $\begin{array}{l}\text { Magnesium Sulfate } \\
16 \mathrm{mEq}\end{array}$ \\
\hline & & $\begin{array}{l}\text { Post-treatment: } 1,000 \\
\text { mL NS over } 1-2 \\
\text { hours }\end{array}$ & \\
\hline Day 2 & & $\begin{array}{l}1,500 \mathrm{~mL} \text { NS over } 2 \\
\text { hours }\end{array}$ & $\begin{array}{l}\mathrm{K} \text { and } \mathrm{Mg} \\
\text { replacement as } \\
\text { needed }\end{array}$ \\
\hline Day 3 or 4 & & $\begin{array}{l}1,500 \mathrm{~mL} \text { NS over } 2 \\
\text { hours }\end{array}$ & $\begin{array}{l}\mathrm{K} \text { and } \mathrm{Mg} \\
\text { replacement as } \\
\text { needed }\end{array}$ \\
\hline RESPONSIVE & \multicolumn{3}{|c|}{ Frequency of visits at least weekly but more frequent if needed } \\
\hline Day $5-21$ & & \multicolumn{2}{|c|}{$\begin{array}{l}\text { Hydration and electrolytes replacement as } \\
\text { needed. }\end{array}$} \\
\hline
\end{tabular}

$\mathrm{K}=$ potassium, $\mathrm{m}=$ meter, $\mathrm{mEq}=$ milliequivalents, $\mathrm{mg}=$ milligram, $\mathrm{Mg}=$ magnesium, $\mathrm{NS}=$ normal saline, op-HD-cis $=$ high dose cisplatin 
홈. 

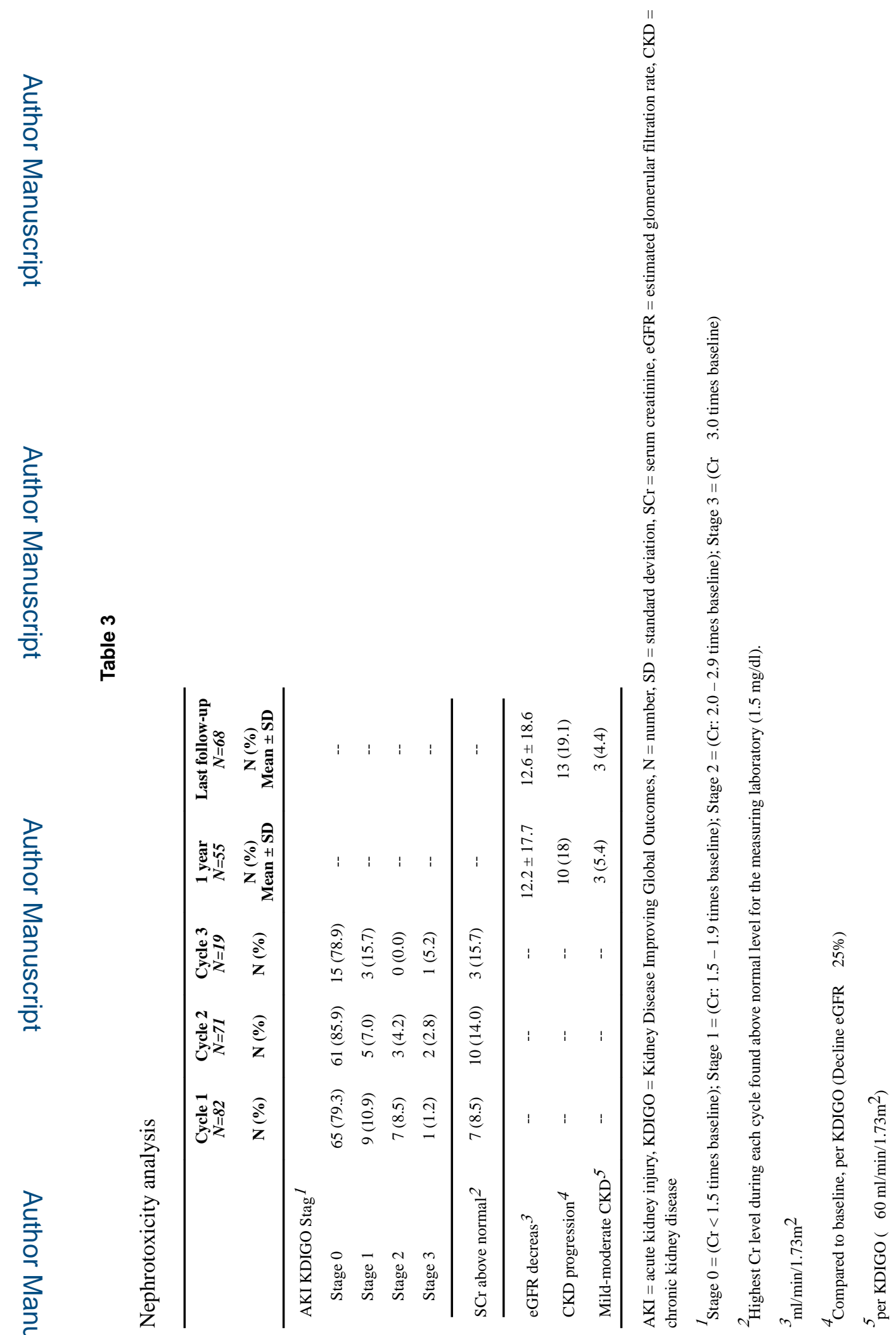

Am J Clin Oncol. Author manuscript; available in PMC 2019 May 01. 


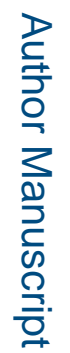

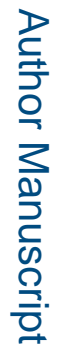

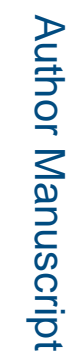

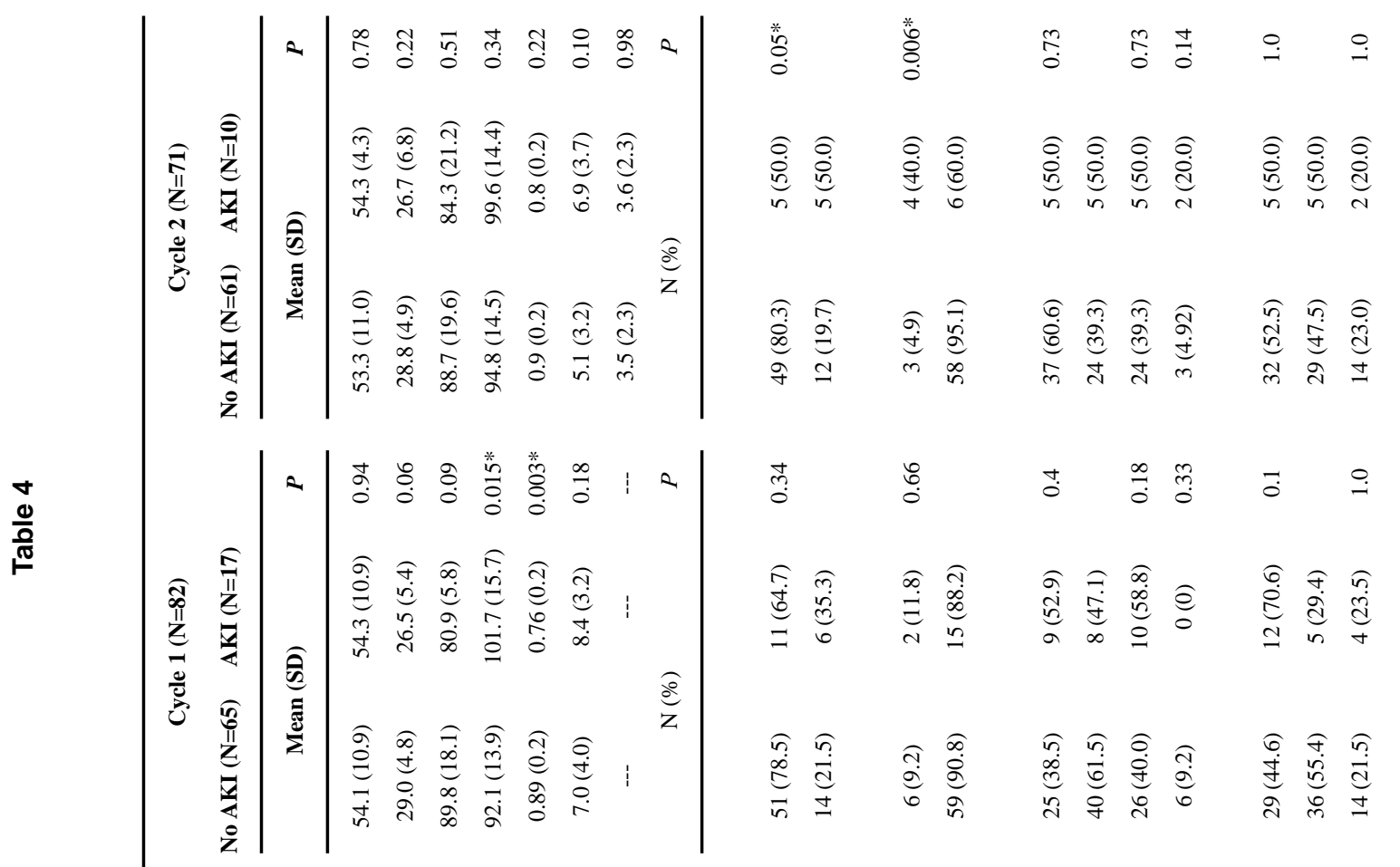

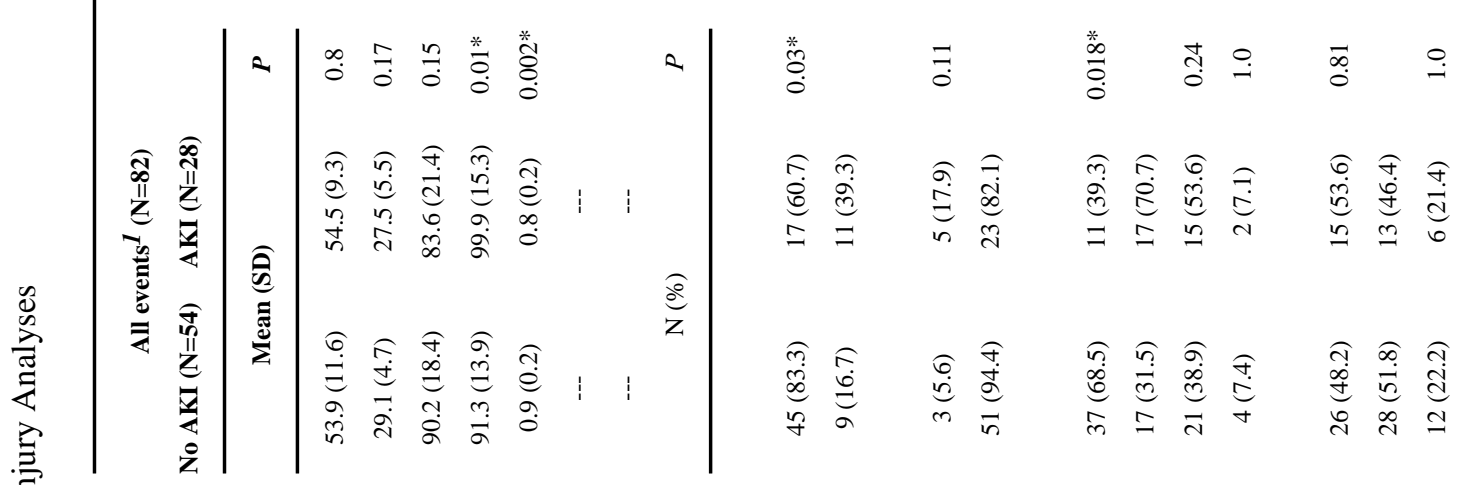

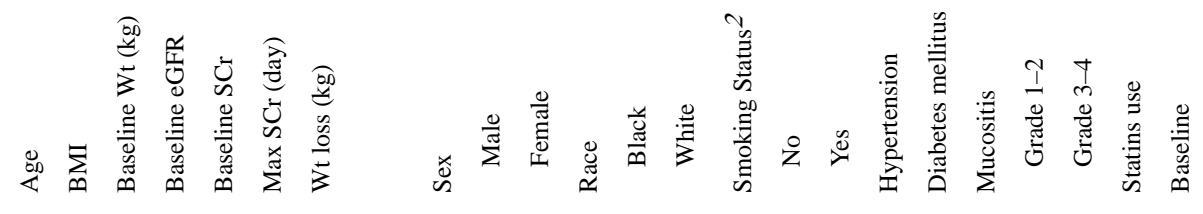

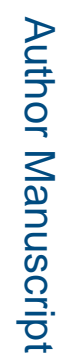




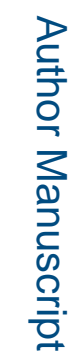

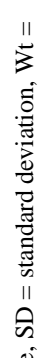

롤

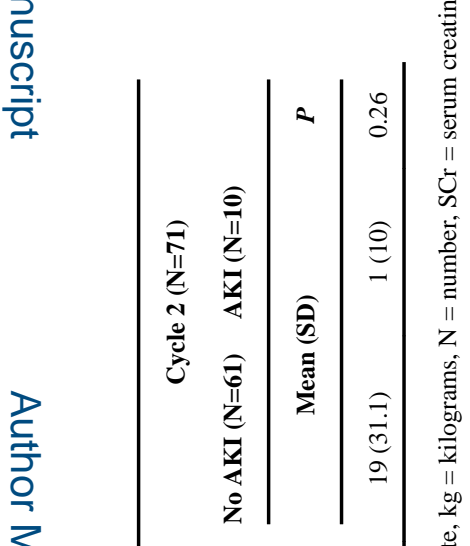

旁 $\mid$ |

음.

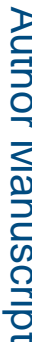

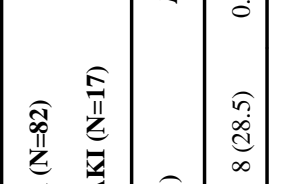

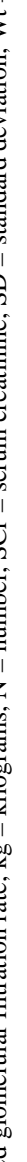

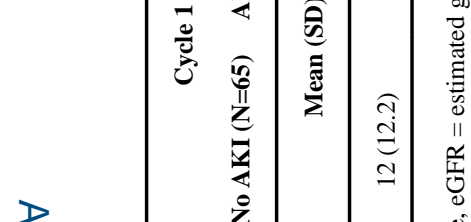

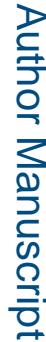

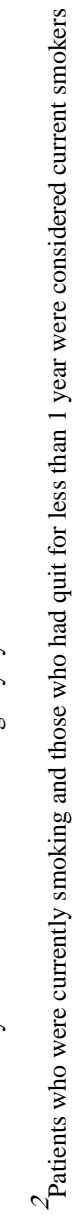

Am J Clin Oncol. Author manuscript; available in PMC 2019 May 01. 


\section{Table 5}

CKD Analysis at 1-year and at the last follow up visit

\begin{tabular}{|c|c|c|c|c|}
\hline & \multicolumn{2}{|c|}{ 1-year REL-eGFR (N=55) } & \multicolumn{2}{|c|}{ Last REL-eGFR (N=68) } \\
\hline & Relative \% (SE) & $\boldsymbol{P}$ & Relative \% (SE) & $P$ \\
\hline \multicolumn{5}{|l|}{ Sex } \\
\hline Male & $0.09(0.02)$ & $0.04^{*}$ & $0.08(0.02)$ & 0.12 \\
\hline Female & $0.21(0.06)$ & & $0.17(0.05)$ & \\
\hline \multicolumn{5}{|l|}{ Race } \\
\hline Black & $0.27(0.11)$ & $0.03^{*}$ & $0.24(0.07)$ & 0.06 \\
\hline White & $0.10(0.02)$ & & $0.09(0.02)$ & \\
\hline \multicolumn{5}{|l|}{ Smoking $A$} \\
\hline Yes & $0.20(0.04)$ & $0.003^{*}$ & $0.15(0.03)$ & 0.10 \\
\hline No & $0.06(0.03)$ & & $0.07(0.03)$ & \\
\hline \multicolumn{5}{|l|}{ Hypertension } \\
\hline Yes & $0.19(0.04)$ & $0.04 *$ & $0.12(0.03)$ & 0.66 \\
\hline No & $0.08(0.03)$ & & $0.10(0.03)$ & \\
\hline \multicolumn{5}{|l|}{ Diabetes mellitus } \\
\hline Yes & $0.20(0.19)$ & 0.54 & $0.06(0.08)$ & 0.57 \\
\hline No & $0.11(0.03)$ & & $0.11(0.02)$ & \\
\hline \multicolumn{5}{|l|}{ Mucositis } \\
\hline Grade $1-2$ & $0.13(0.03)$ & 0.64 & $0.11(0.03)$ & 0.70 \\
\hline Grade 3-4 & $0.11(0.04)$ & & $0.10(0.03)$ & \\
\hline \multicolumn{5}{|l|}{ Statins use } \\
\hline Yes & $0.11(0.06)$ & 0.88 & $0.07(0.05)$ & 0.34 \\
\hline No & $0.12(0.03)$ & & $0.12(0.05)$ & \\
\hline \multicolumn{5}{|l|}{$\mathrm{BUN} / \mathrm{Cr} \geq 20$} \\
\hline Yes & $0.11(0.04)$ & 0.89 & $0.10(0.04)$ & 0.96 \\
\hline \multirow[t]{3}{*}{ No } & $0.12(0.03)$ & & $0.10(0.03)$ & \\
\hline & \multicolumn{2}{|c|}{$\begin{array}{l}\text { Correlation with } \\
\text { 1-year REL-eGFR }\end{array}$} & \multicolumn{2}{|c|}{$\begin{array}{l}\text { Correlation with } \\
\text { last REL-eGFR }\end{array}$} \\
\hline & $\mathrm{r}$ & $P$ & $\mathrm{R}$ & $P$ \\
\hline Age & -0.17 & 0.21 & -0.14 & 0.27 \\
\hline BMI & -0.08 & 0.52 & -0.19 & 0.13 \\
\hline Baseline weight & -0.16 & 0.24 & -0.23 & 0.06 \\
\hline Weight loss 3 month & -0.03 & 0.79 & -0.05 & 0.66 \\
\hline Baseline eGFR & 0.25 & 0.07 & 0.33 & $0.007 *$ \\
\hline Baseline SCr & -0.22 & 0.10 & -0.31 & $0.01 *$ \\
\hline Cisplatin dose & 0.05 & 0.73 & 0.06 & 0.64 \\
\hline I.V. fluid $B$ & 0.17 & 0.20 & 0.32 & $0.008 *$ \\
\hline I.V. $\mathrm{M}^{B}$ & 0.28 & $0.04 *$ & 0.25 & $0.04 *$ \\
\hline
\end{tabular}


1-year REL-eGFR $=$ observed relative percent change in eGFR at 1 -year evaluation, $\mathrm{BMI}=$ body mass index, $\mathrm{BUN}=$ blood urea nitrogen, $\mathrm{CKD}=$ chronic kidney disease, $\mathrm{Cr}=$ creatinine, $\mathrm{eGFR}=$ estimated glomerular filtration rate, I.V. $=$ intravenous, last REL-eGFR $=$ observed relative percent change in eGFR at the last follow-up evaluation, $\mathrm{Mg}=$ magnesium, $\mathrm{N}=$ number, $\mathrm{r}=$ correlation, $\mathrm{SE}=$ standard error, $\mathrm{SCr}=$ serum creatinine

$A_{\text {Patients who were currently smoking and those who had been quit for less than } 1 \text { year were considered current smokers }}$

$B_{\text {In addition to hydration protocol }}$ 